\title{
Narrative Scenarios for a Humanistic Approach to Tech- nology Critique - A Case Study
}

\author{
Jaime Oberle *, Elke Brucker-Kley ${ }^{\dagger}$, \\ Thomas Keller ${ }^{\dagger}$
}

\begin{abstract}
Are narrative scenarios effective artifacts to trigger an interdisciplinary and transdisciplinary discourse that results in actionable design criteria for the future co-existence of humans and intelligent machines? To answer this question, a multilinear narrative illustrating the impact of emerging technologies on the future of vocational education was developed, and a small field study was conducted to evaluate its effects. The findings support the hypothesis that narratives can trigger a reflection about new and disruptive technologies and can thereby help to propagate a humanistic view of our ever more technology-driven world.
\end{abstract}

Keywords: responsible innovation, vocational education, narrative scenarios, futures research

\section{Introduction}

The domain of vocational education in Switzerland discussed in this case study is characterized by the tendency that actors in the vocational education system - namely schools and teachers have certain inhibitions about the digital transformation and tend to feel overwhelmed by it [1]. According to a report by the Swiss Federal Institute for Vocational Education and Training, this leads to a growing gap in digital skills between teachers and students, in part because many students can develop a knowledge lead in their apprenticing companies. This may result in a fundamental change in the role of teachers in basic vocational education, undermining their knowledge lead and transforming their function from subject matter experts to learning coaches. Furthermore, knowledge about emerging technologies of corporate and individual actors in vocational education is characterized as patchy and technologies are not always used effectively [2, p. 4]. Thus, the use of advanced technologies may happen unprepared and thinking about their consequences may come too late.

The obvious reactions to this situation are education policy strategies and action plans that define and promote promising key technologies and skills top-down [3]. What seems equally relevant,

\footnotetext{
* BBW Vocational School, Winterthur

${ }^{\dagger}$ ZHAW Zurich University of Applied Sciences, Switzerland
} 
however, are the contextual and individual factors in the everyday lives of the people involved such a digital transformation process. To what extent are teachers and learners willing to use certain emerging technologies and what experiences, expectations and fears do they associate with these technologies?

Rational arguments and extrinsic incentives are not necessarily at the forefront when humans more or less consciously - decide to use or not to use emerging technologies. Our research, in which this case study is embedded, is influenced by humanistic approaches of technology criticism and technophilosophy [4], [5]. From this perspective humans are not regarded as "mindless victims of technology" but as "agents of cultural change" [6, p. 154]. The focus is on better understanding the socio-cultural and psychological determinants that cause people to embrace or fear technologies. Motivation theory is applied in psychology to explain such human choices. Self-Determination Theory is a major motivation theory and has also proven to be helpful in capturing the intrinsic motivation of people to use technology [7], [8]. Self-Determination Theory consists of six mini-theories according to Ryan and Deci [9]. The mini-theory called "Basic Needs Theory" proposes that the motivation for human behavior depends on the extent to which three basic psychological needs can be satisfied: These basic needs are competence, autonomy and social relatedness, which represent prerequisites for realizing the well-being of an individual $[10$, p. 153]. If these three target parameters are applied to a concrete situation in the domain of vocational education, which confronts teachers and students with emerging technologies, it should be possible to draw conclusions about the motivations and situational well-being of the persons involved. For this purpose, it is necessary to create such situations embed them in a context and make them experienceable. Thereby both the loss and gain of autonomy, competence and social relatedness caused by the use of emerging technologies becomes experienceable. These experiences can then form the common ground for discussing necessary boundaries and design criteria for emerging technologies.

\section{Research Objective}

The overarching goal of the research presented is to trigger a broad social discourse on the desirability and designability of our technological future [11]-[13].

Multi-linear scenarios shall confront the readers with decisions and allow them to experience different versions of the future in a specific domain, in this case vocational education. The readers are forced to leave the role of the distanced observer and experience concrete situations involving advanced technologies in the scenarios. The individual reflection and discourse will then be grounded in this emotional, lifelike experience.

The artifact in this case study is a multilinear story, which allows to experience how the use of advanced technologies might affect everyday life in a vocational school and the relationship between learner and teacher in the future. The reader, in the role of the teacher, is confronted with decisions whether and to what extend new technologies will be used. Depending on the individual decisions, the readers experience different versions of the future. The opportunities and risks of these technologies should thus become tangible. The dilemmas at the decision points trigger emotions and let the readers immerse themselves in the story.

The multilinear narrative is to be realized by means of a software artifact, in the form of a so called Twine [14], i.e. a hypertext that readers can interact with via an Internet browser. The story is embedded in a context that includes different relevant environmental factors. Decisions of the observer can have a parametric effect on the selection of influencing environmental factors as 
well as on the use of the technologies in the given situation. The possible parameter values, in turn, depend on the situation in which the reader acts and takes decisions.

The viewer's interaction data is recorded by a tracking system and is transparently displayed at the end of the experience. This artifact is to be made available to a broad public via Internet beyond the context of the presented case study [15] . However, a quantitative evaluation of collected interaction data is not the primary subject of this case study. The tracking results are initially just intended to provide a basis for discussion for the qualitative evaluation of the artifact based on the experiences of the test persons.

\section{Related Research and Research Approach}

This research was conducted applying a Design Science Research approach [16] by implementing a software artifact in the form of a multilinear narrative and by validating its impact with a tracking system, a short pre- and post- experience survey and qualitative interviews. The methods used to create emotionally engaging but still plausible narrative scenarios are described in the following sections.

Futurology has undergone various paradigm shifts since the middle of the 20th century [17, p. 12]. Primarily quantitative-normative approaches were expanded by qualitative-narrative approaches in order to reflect the increasing multifaceted nature of our future. The creative-narrative approach to scenarios chosen for this case study is characterized above all by the assumption that there is not a single probable and desirable future, but that several, possibly extremely different variants of the future exist. In order to develop these variants systematically and well founded, the scenarios were developed in four phases [17, pp. 19-21]:

(1) Determination of the context of the scenario, its actors and driving political, economic, sociocultural, legal and environmental factors using a PESTLE analysis [18].

(2) Identification of key factors and key technologies shaping the future of the domain, i.e. vocational education

(3) Analysis of various extreme future manifestations of key factors and key technologies in a morphological matrix [19]

(4) Development of concrete scenarios using Science Fiction Prototyping [20]

The Science Fiction Prototyping method began within Intel Corporation in 2010. Intel's futurist B.D. Johnson's motivation was to use science fiction as input into the technology innovation process to encourage engineers to think about their technological developments in a more humanistic way [16]. Since then, science fiction prototyping has been applied both in industrial innovation processes [17] and in research and teaching [18], [19] to reflect on the consequences of technological developments in a particular context. Adding interactivity to Science Fiction Prototypes helps to intensify the experience for the recipient [20]. Multilinear storytelling enables interactivity by confronting the reader with decisions and thus encourages thinking in alternatives .

Figure 1 illustrates the five steps to accomplish Science Fiction Prototyping and to develop the narrative according to Johnson [16, p. 25ff]. 


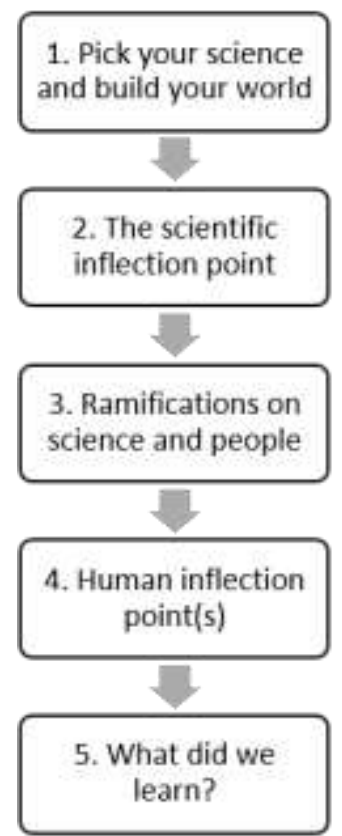

What are the key technologies changing the face of vocational education? Under which future conditions (scenography)?

What happens if these

technologies are placed into the everyday life of a future vocational school?

How will the teachers and students adapt and change because of these technologies (Self-Determination Theory)?

What if things go wrong or to the extreme? How will the actors react to escape or shine?

What are possible implications for the design of the technology from a human perspective?

Figure 1: The five steps for Science-Fiction Prototyping applied to the case study

Step 2 and 4 of the Scientific Prototyping Process (Figure 1)) are the most creative ones both for the author and the recipients of the narrative. Interactivity is enabled for the recipients by means of multilinear storytelling [21], [22]. In multilinear stories decision points allow for variation in the narrative and the story is thus divided into several storylines [23]. This results in a decision tree, in which individual storylines can be merged again. Techniques for multilinear storytelling to increase the engagement of the reader have been developed for textual and visual formats since the 1970s and have been refined for the increasingly powerful interaction capabilities of hypertexts, video games and most recently Virtual Reality [24].

\section{The Development of the Multilinear Narrative}

The multilinear narrative was designed and implemented in the four-phased approach according to Johnson as outlined in the previous chapter [16].

(1) At first, in order to identify the external factors shaping the future of vocational education globally and in Switzerland a broad literature search was conducted and the results were synthesized in a PESTLE analysis [25].

(2) Second, the large pool of individual factors was clustered into seven key factors, shaping vocational education:

- Social and individual wellbeing and mental health

- Individual mobility

- Privacy

- Education policy and flexibilization of education

- Education funding and equal opportunities

- Economic stability and unemployment

- Climate-related problems and restrictions and environmental pollution 
Starting from the meta studies of Alexander et al. [26] and Seufert [27] the following technologies were identified as key factors potentially changing the face of vocational education in the future and were explored in more detail:

\section{Blockchain, or distributed computing}

Storage and safekeeping of performance results, diplomas, contracts, and use as a solution for identity management. [28]

\section{Virtual Reality}

Practical simulations in face-to-face teaching, as well as complete handling of distant or hybrid learning. [29], [30]

\section{Artificial Intelligence}

Enabling adaptive learning and individual support of students, depending on their interaction [31]

\section{Virtual assistants}

Providing administrative and organizational services, as well as personal advice and assistance. [32]

\section{Cognitive Computing}

Processing and adaptive delivery of large amounts of structured and unstructured content, automated correction and evaluation of content (e.g. exercises or exams), and provision of advanced means of human-computer interaction. [33]

(3) Third, two morphological matrices were created for the seven key factors and the key technologies. In both morphological matrices four extreme future manifestations for each key factor and key technology were formulated as premises.

According to Ritchey [34, p. 1] and Kosow \& Gassner [35, p. 49] a morphological analysis is suitable to develop scenarios in a creative yet systematic manner. By linking the morphological matrices, a parameter space is created which delimits the scenarios and allows parameters to be orchestrated into different storylines. Thereby the morphological analysis results in extreme, provocative alternatives of scenarios whose effects can be related to the manifestation of key factors and technologies [36, p. 31]. As such, a methodical and replicable basis for the subsequent creative process is established.

(4) Fourth, the scenography and the various storylines of the multilinear narrative were developed by applying the Science Fiction Prototyping method, which was outlined in the previous chapter. Three extreme storylines were implemented in an interactive hypertext, a so called Twine (Figure 2), which is accessible via Internet browser [15]. The result is a multilinear story, which allows to experience how the use of advanced technologies might affect everyday life in a vocational school and the relationship between students and teacher in the future. The reader, in the role of the teacher, is confronted with decisions whether and to what extend new technologies enabled by Blockchain, Virtual Reality, Virtual Assistants and Cognitive Computing will be used. Depending on these decisions, different courses of action result with different consequences for the teacher and the students. 


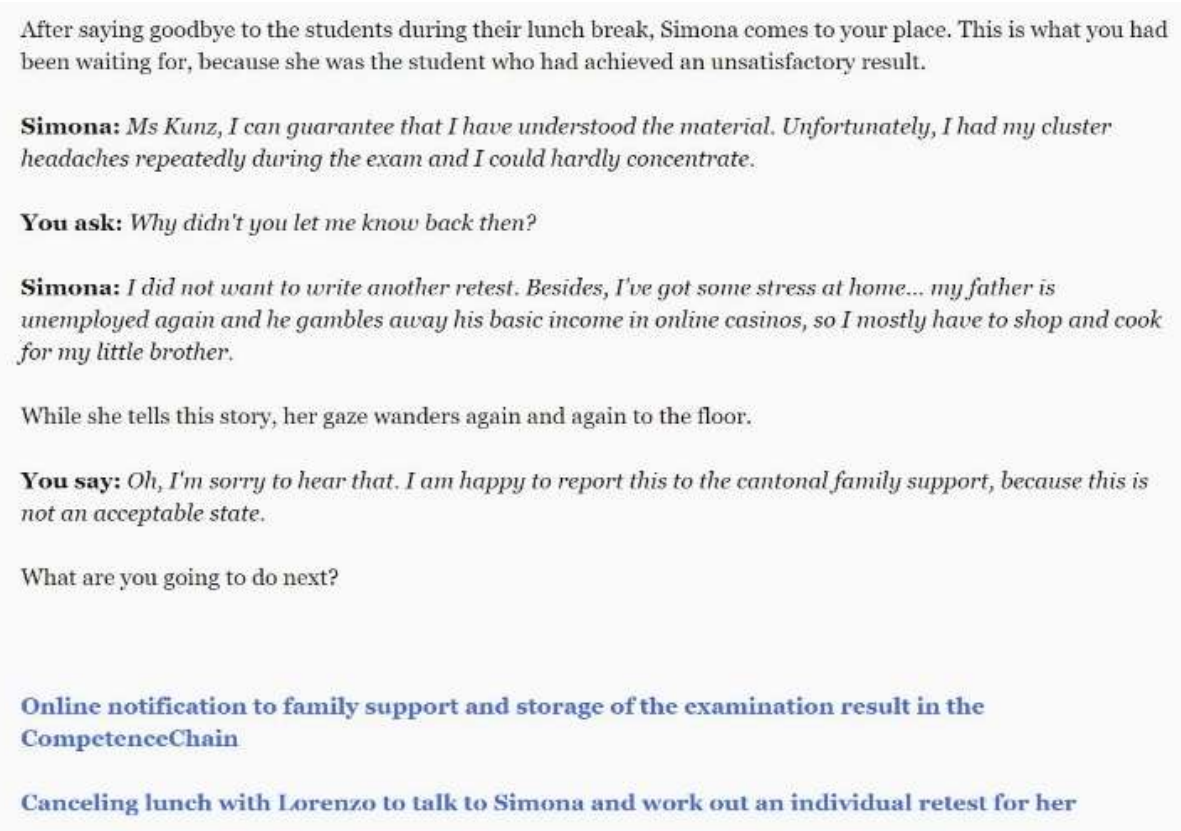

Figure 2: Extract from the Twine, illustrating the options for the reader

The first iteration of the Twine was evaluated in a think-aloud test with a limited number of test persons who were then excluded from the actual field study [37]. Based on the results usability and dramaturgical quality of the artifact were improved. In course of the iterative design and implementation process the authors continuously validated whether the following predefined quality criteria for the multilinear narrative, were fulfilled [35, p. 28]:

- Plausibility: The developments in the scenarios must be regarded by the audience as fundamentally possible, but not necessarily as probable.

- Consistency: Individual storylines of the multi-linear narrative must be coherent and must not contain any contradictions.

- Comprehensibility: Scenarios must be understandable and sufficiently detailed.

- Discriminatory power: Extreme storylines must be clearly separated from one another so that they can be perceived as alternatives.

- Transparency: The framing conditions and the scenography must be comprehensible. Premises must be defined and explained.

\section{$5 \quad$ Field Study and Findings}

The impact of the final iteration of the artifact was validated in a small qualitative field study. 37 test persons were invited to participate. The invitees were either teachers or lecturers, holders of an academic degree in human sciences (such as psychology or philosophy) or engineers from the Education Technology (EdTech) industry. 9 test persons agreed to participate in a qualitative post-experience interview (Table 1).

Immediately before and after going through the narrative, a short online survey was displayed to identify the attitude towards the technologies involved on a Likert scale (very open - curious neutral - skeptical - rejecting). In addition, the test persons could rate in the post-survey to what 
extend they considered the experienced future to be imaginable on the one side and desirable on the other.

Table 1: Interviewees

\begin{tabular}{lll}
\hline Gender & Age & Academic Degree \\
\hline $\mathrm{M}$ & 33 & Phd in Psychology \\
\hline $\mathrm{M}$ & 48 & MSc. in philosophy \\
\hline $\mathrm{M}$ & 60 & Mechanical Engineer \\
\hline $\mathrm{M}$ & 34 & BSc Applied Psychology \\
\hline $\mathrm{F}$ & 45 & Dipl. Business Economist \\
\hline $\mathrm{F}$ & 34 & Phd in Psychology \\
\hline $\mathrm{M}$ & 53 & Civil and software engineer \\
\hline- & 54 & Software Engineer \\
\hline
\end{tabular}

While the participants interacted with the multilinear narrative, selections and inputs were continuously stored in the background. The date served as an input for the interviews that took place immediately after the experience via video conference. The interviews were semi-structured, and the collected interaction data were used to deepen the discussion in specific areas. The usage time of the artifact of the nine interview partners was between 20 to 49 minutes and on average about 30 minutes, which suggests that the interview partners seriously dealt with the story and that no "fatigue effect" occurred [38]. The subsequent interviews lasted on average about 40 minutes, which confirms this conclusion accordingly.

The interview questions aimed to find out whether a reflection process was triggered among the test persons while or after using the artifact. The analysis of the pre- and post-survey confirmed that two of the interviewees did not state any change in their attitude towards the technologies described. Four indicated a slight change in their attitude, while three interviewees showed a clear change in their attitude. It should be added that the artifact was never intended to increase skepticism. Any change in attitude also towards a more open attitude is seen as an indicator of a more differentiated view.

It is noticeable that 6 of 9 interview partners consider the experienced future to be well or very well imaginable, which means that the scenarios were able to convey a plausible version of the future. 2 found the experienced future potentially imaginable and only 1 test person considered the future to be rather unimaginable. Interestingly, none of the test persons found the experienced future to be absolutely or rather desirable. 6 test persons rated the experienced future as partially desireable, 2 as rather not and 1 as absolutely not desireable. From the interview responses it can be concluded that the loss of autonomy, competence and social relatedness was felt more strongly than the opportunities gained through the use of technology. In relation to the artifact, it can be concluded that the dystopian elements had a strong effect, while the utopian elements became less tangible, at least in the context of this small field study.

All 9 interviewees stated that they could imagine using this multilinear narrative to trigger a discourse on our digital future in a group of teachers or lecturers.

\section{Conclusions}

Using vocational training as an example, this case study described a systematic yet creative approach for developing narrative multi-linear future scenarios that allow a reflection on the desirability and imaginability of our technologized future. 
Whether these scenarios are capable of triggering a broad social discourse could not be validated within the framework of the limited field study. However, the reactions of the interviewees suggest that the artifact has the potential to provoke reflections and a more differentiated attitude towards emerging technologies.

The systematic analyses (PESTLE, morphological analysis) to set the stage for the narrative and its multilinear storylines have proven to be effective. The factors and premises behind the three portrayed extreme versions of the future can thus be traced back. In a further iteration, parameters could potentially be changed to experiment for example with more utopian or even more dystopian storylines.

Science Fiction Prototyping as a method was helpful to structure the creative process and to strictly adhere to the human perspective.

The biggest challenge in the development of the artifact is certainly to create purely narrative but not normative scenarios. It would be naïve to believe that a narrative scenario can be designed in a completely objective way. Multilinearity allows for alternatives and thereby for a more differentiated picture of the future. Nevertheless, it is important to acknowledge that scenarios do not develop a subjective and potentially political character only when they are experienced, but that political qualities are inevitably embedded in each artifact, as described by Langdon Winner in his essay "Do Artifacts have Politics" [39].

The group of test persons was definitely limited, not only in terms of quantity but also in terms diversity. All of the interviewees hold an academic degree and represent either the perspective of teachers or providers of educational technology. The perspective of other actors in the domain of vocational education, most notably of students but also of decision makers from educational authorities have only been considered in the creation of the scenario, but not in the field study. Therefore, the effectiveness of the artifact with other target groups has not been proven and the conclusions must be considered against the background of these limitations.

Future research is needed and should use the artifact to collect quantitative data from a broad spectrum of relevant target groups in the domain of vocational education. With more data, correlations could also be drawn to the specific paths that the readers have effectively followed in the scenario. However, the suitability of the artifact for quantitative research still remains to be verified.

A possible next step on the qualitative research front would be to examine in a larger context, for example in the format of a future workshop [40], whether the experience with the multilinear narrative enables the actors to discuss constructively on a common basis and to formulate concrete design criteria for the respective technologies. In this way one could address the question of whether narrative multi-linear scenarios can trigger a broad but also effective social discourse about our digital future.

\section{References}

[1] C. Schmitt, "Warum die Bildung Angst vor der Digitalisierung hat," Coaching, innovatives Lernen, Weiterbildung, Jan. 04, 2016. http://www.bildungsdesign.ch/2016/01/04/warum-diebildung-angst-vor-der-digitalisierung-hat/ (accessed Nov. 16, 2019).

[2] J. Schweri, I. Trede, and I. Dauner, "Digitalisierung und Berufsbildung. Herausforderung und Wege in die Zukunft.," Eidg. Hochschulinstitut für Berufsbildung EHB, 2018. 
[3] Staatssekretariat für Bildung, Forschung und Innovation, "Leitbild und Stossrichtungen," Berufsbildung 2030, 2018. https://berufsbildung2030.ch/de/leitbild-und-stossrichtungen (accessed Nov. 09, 2019).

[4] H. Poser, Homo Creator: [Technology as Philosophical Challenge]Technik als philosophische Herausforderung. Springer, 2016.

[5] A. E. Taylor, "Body and technology: Reframing the humanistic critique," Janus Head, vol. 12, no. 1, pp. 12-1, 2011.

[6] E. Rose, "The Errors of Thamus: An Analysis of Technology Critique," Bulletin of Science, Technology \& Society, vol. 23, no. 3, pp. 147-156, Jun. 2003, doi: 10.1177/0270467603023003001.

[7] D. Peters, R. A. Calvo, and R. M. Ryan, "Designing for Motivation, Engagement and Wellbeing in Digital Experience," Front Psychol, vol. 9, May 2018, doi: 10.3389/fpsyg.2018.00797.

[8] Y. Lee, J. Lee, and Y. Hwang, "Relating motivation to information and communication technology acceptance: Self-determination theory perspective," Computers in Human Behavior, vol. 51, pp. 418-428, Oct. 2015, doi: 10.1016/j.chb.2015.05.021.

[9] R. M. Ryan and E. L. Deci, "Self-determination theory and the facilitation of intrinsic motivation, social development, and well-being," Am Psychol, vol. 55, no. 1, pp. 68-78, Jan. 2000, doi: 10.1037//0003-066x.55.1.68.

[10] J. Reeve, "A Self-determination Theory Perspective on Student Engagement," in Handbook of Research on Student Engagement, S. L. Christenson, A. L. Reschly, and C. Wylie, Eds. Boston, MA: Springer US, 2012, pp. 149-172. doi: 10.1007/978-1-4614-2018-7_7.

[11] E. Brucker-Kley and T. Keller, "Exploring the Potential of Immersive Narrative Scenarios to Identify Design Criteria for our Digital Future(s)," in 2019 8th International Congress on Advanced Applied Informatics (IIAI-AAI), Toyama, Japan, Jul. 2019, pp. 499-504. doi: 10.1109/IIAI-AAI.2019.00108.

[12] E. Brucker-Kley and T. Keller, Digital Futures : Szenarien am Rande der Technologischen Singularität. ZHAW Zürcher Hochschule für Angewandte Wissenschaften, 2020. doi: 10.21256/zhaw-19471.

[13] E. Brucker-Kley and T. Keller, "Beyond Digitalization: 'My Boss Is Artificial," in Knowledge, People, and Digital Transformation: Approaches for a Sustainable Future, F. Matos, V. Vairinhos, I. Salavisa, L. Edvinsson, and M. Massaro, Eds. Cham: Springer International Publishing, 2020, pp. 37-54. doi: 10.1007/978-3-030-40390-4_4.

[14] "Twine / An open-source tool for telling interactive, nonlinear stories." https:/twinery.org/ (accessed Sep. 04, 2019).

[15] J. Oberle, "Zukunftsszenarien für die berufliche Grundbildung / The Future of Vocational Education,” Digital Futures, Sep. 23, 2020. https://digitalfutures.ch/zukunftsszenarien-fuerdie-berufliche-grundbildung/ (accessed Nov. 08, 2020). 
[16] B. D. Johnson, "Science Fiction Prototyping: Designing the Future with Science Fiction," Synthesis Lectures on Computer Science, vol. 3, no. 1, pp. 1-190, Apr. 2011, doi: 10.2200/S00336ED1V01Y201102CSL003.

[17] E. Atherton and B. D. Johnson, "Science Fiction Prototyping at Work," Computer, vol. 49, no. 8, pp. 109-111, Aug. 2016, doi: 10.1109/MC.2016.229.

[18] M. Burnam-Fink, "Creating narrative scenarios: Science fiction prototyping at Emerge," Futures, vol. 70, pp. 48-55, Jun. 2015, doi: 10.1016/j.futures.2014.12.005.

[19] A. Merrie, P. Keys, M. Metian, and H. Österblom, "Radical ocean futures-scenario development using science fiction prototyping," Futures, vol. 95, pp. 22-32, Jan. 2018, doi: 10.1016/j.futures.2017.09.005.

[20] J. Pirker, C. Gütl, P. Weghofer, and V. Feichtner, "Interactive Science Fiction Prototyping in Virtual Worlds: Fundamentals and Applications," International Journal of Recent Contributions from Engineering, Science \& IT (iJES), vol. 2, no. 3, pp. 46-52, Aug. 2014.

[21] M. O. Riedl and V. Bulitko, "Interactive Narrative: An Intelligent Systems Approach," AI Magazine, vol. 34, no. 1, pp. 67-67, 2013, doi: 10.1609/aimag.v34i1.2449.

[22] J. H. Murray, Hamlet on the Holodeck. New York: Free Press, 1997.

[23] W. M. Wang and C. F. Cheung, "A computational narrative simulation system for constructing multi-linear narratives in knowledge management," Journal of knowledge management practice, vol. 14, no. 3, pp. 1-18, 2013.

[24] R. Crawford and Y. Chen, "From hypertext to hyperdimension Neptunia: The future of VR visual novels: The potentials of new technologies for branching-path narrative games," in 2017 23rd International Conference on Virtual System Multimedia (VSMM), Oct. 2017, pp. 1-7. doi: 10.1109/VSMM.2017.8346298.

[25] Salzburg Research, "PESTLE-Technik | Methodenpool," Sep. 18, 2019. https://methodenpool.salzburgresearch.at/methode/pestle-technik/ (accessed Sep. 18, 2019).

[26] B. Alexander et al., Educause Horizon report: 2019 Higher Education edition. 2019.

[27] S. Seufert, "Berufsbildung 2030: Flexibilisierung der Berufsbildung im Kontext fortschreitender Digitalisierung," 2018. [Online]. Available: https://www.sbfi.admin.ch/dam/sbfi/de/dokumente/2018/06/2030-flexibilisierung.pdf.download.pdf/Bericht_SR_BB2030_Flexibilisierung.pdf

[28] A. Grech and A. F. Camilleri, Blockchain in Education. Luxembourg: pedocs, 2017. Accessed: Oct. 21, 2020. [Online]. Available: http://nbn-resolving.de/urn:nbn:de:0111-pedocs150132

[29] T. Keller, E. Brucker-Kley, and C. Wyder, "Virtual reality and its impact on learning success," 2020, pp. 78-86. Accessed: Oct. 21, 2020. [Online]. Available: https://digitalcollection.zhaw.ch/handle/11475/19981 
[30] T. Keller, P. Glauser, N. Ebert, and E. Brucker-Kley, Virtual Reality at Secondary School -First Results. International Association for the Development of the Information Society, 2018. Accessed: Oct. 21, 2020. [Online]. Available: https://eric.ed.gov/?id=ED600587

[31] "Artificial Intelligence In Education: Promises and Implications for Teaching and Learning - Open Research Online.” http://oro.open.ac.uk/60255/ (accessed Oct. 21, 2020).

[32] S. Daley and J. Pennington, “Alexa the Teacher's Pet? A Review of Research on Virtual Assistants in Education," Jun. 2020, pp. 138-146. Accessed: Oct. 21, 2020. [Online]. Available: https://www.learntechlib.org/primary/p/217296/

[33] M. Coccoli, P. Maresca, and L. Stanganelli, "Cognitive computing in education," Journal of e-Learning and Knowledge Society, vol. 12, no. 2, May 2016, Accessed: Oct. 21, 2020. [Online]. Available: https://www.learntechlib.org/p/173468/

[34] T. Ritchey, "Futures Studies using Morphological Analysis," Swedish Morphological Society, 2009.

[35] H. Kosow and R. Gassner, Methoden der Zukunfts-und Szenarioanalyse Überblick, Bewertung und Auswahlkriterien. 2008.

[36] K. Steinmüller, "Methoden der Zukunftsforschung - Langfristorientierung als Ausgangspunkt für das Technologie-Roadmapping," in Technologie-Roadmapping, M. G. Möhrle and R. Isenmann, Eds. Berlin, Heidelberg: Springer Berlin Heidelberg, 2017, pp. 29-46. doi: 10.1007/978-3-662-52709-2_3.

[37] N. Döring and J. Bortz, Forschungsmethoden und Evaluation in den Sozial- und Humanwissenschaften, 5. vollständig überarbeitete, Aktualisierte und erweiterte Auflage. Berlin Heidelberg: Springer, 2016.

[38] American Psychological Association, "Fatigue Effect - APA Dictionary of Psychology," May 10, 2020. https://dictionary.apa.org/fatigue-effect (accessed May 10, 2020).

[39] L. Winner, “Do Artifacts Have Politics?,” Daedalus, vol. 109, no. 1, Art. no. 1, 1980.

[40] P. Weinbrenner, "Zur Theorie und Praxis von Zukunftswerkstätten,” 2002. 